\title{
The history of chemical laboratories: a thematic approach
}

\author{
Peter J. T. Morris ${ }^{1}$ \\ Received: 27 January 2021 / Accepted: 25 March 2021 / Published online: 22 June 2021 \\ (c) The Author(s), under exclusive licence to Springer Nature Switzerland AG 2021
}

\begin{abstract}
Chemical laboratories have existed since the late sixteenth century. Two basic designs have dominated this history: a furnacecentred laboratory based on earlier alchemical workshops up to around 1820 and then a design based on the use of the Bunsen burner with benches and bottle racks since the 1850s (the "classical" laboratory). New designs with a focus on health and safety began to appear at the end of the twentieth century. There has been an important interaction between the design of the laboratory and chemical practice, including how chemistry was taught. In particular, the introduction of running water and piped gas was crucial to the creation of the "classical" laboratory in the 1860s. One aspect of the classical laboratory which has disappeared is the chemical museum. This article considers university, industrial and school laboratories, and also the social organisation of the laboratory. Finally, the article considers the future of chemical laboratories and chemical practice.
\end{abstract}

Keywords Chemical laboratory $\cdot$ History $\cdot$ Education $\cdot$ Academia $\cdot$ Industry

\section{Introduction}

This is a history of the chemical laboratory, but it cannot aim to be comprehensive and thus it is important to understand what it will cover and what it will not. It is a history of the chemical laboratory and hence it will not cover the history of physical or biological laboratories, although they have their origins, at least in part, in the chemical laboratory. Nor will any attempt be made to cover every style or kind of chemical laboratory, but several different types will be discussed. The main purpose of this article is to analyse what the aim of having a chemical laboratory was initially and how it has changed over the centuries. In particular, given the nature of the journal in which this article is appearing, I seek to get the reader to think about what a laboratory is, what it contains and what people do in it. It is noteworthy that the history of the chemical laboratory is one of long periods of stability punctuated by periods of rapid change.

Before we can begin, we have to define what a chemical laboratory is. It is best and simplest to describe it as the space in which chemists carry out their practical work. However, even if properly understood, the term laboratory is

Peter J. T. Morris

peter.morris@sciencemuseum.ac.uk

1 University College London and Science Museum, London, UK ambiguous. It can refer to a single room in which scientific operations take place or to a building which contains these laboratories. Here, the term laboratory will be used only for the room and the building will be called a laboratory building. No attempt will be made here to define chemistry, beyond being the practical activities carried out by people who self-identify as chemists. Indeed, the activities performed in chemical laboratories in the period covered by this article extend out to metallurgy and physics on one side and pharmacy and biochemistry on the other. Nor has the passage of time seen a narrowing of what constitutes chemistry in terms of its laboratories. The last laboratory considered in detail in this article-the chemical research laboratory at Oxford - contains laboratories dedicated to biochemistry and biological chemistry.

\section{Discussion points:}

-What is a laboratory?

-What is distinctive about a chemical laboratory? 


\section{The birth of the laboratory}

Before the late sixteenth century, there were no laboratories. To be precise, there was no such word as "laboratory" until that period. The word first appeared in Latin for the workplace of an alchemist in the 1580s and in English for the same purpose in 1592. Essentially the Latin word laboratorium means a workshop, and before there were any laboratories, alchemists in common with other craft workers had workshops. There was no standard model for an alchemical workshop, but generally they contained a furnace, apparatus for distillation and perhaps some provision for more gentle forms of heating such as the sand bath or fermenting dung. However, there was nothing special about the workshop itself. At this point, we may reflect that there need not be anything special about the room in which chemistry itself is carried out. Chemistry can be carried out in a kitchen, a living room or a garden shed, and often was carried out in such places at least until the mid-twentieth century. Many school children performed at least rudimentary chemical experiments in their parents' garden shed up to that time, as the author of this article did. Indeed, some of these experiments were quite ambitious: For example, I made boron nitride, sodium ferrate(VI) and iodoform in my shed in the early 1970s.

However, these domestic settings were not laboratories. A laboratory is designed for carrying out chemical operations in a way that a garden shed is not. There were two processes at work which helped to create the chemical laboratory. Craft workers in the German metal industry-who may have regarded themselves as alchemists or not- - began to develop more elaborate workplaces in the sixteenth century and equally crucially these workplaces were illustrated and discussed in two important books, De Re Metallica (On the Nature of Metals) by the German scholar Georgius Agricola in 1556 and especially the Beschreibung allerfürnemisten mineralischen Ertzt und Berckwercksarten (Description of Leading Ore Processing and Mining Methods) by the Bohemian metallurgist Lazarus Ercker in 1574 (Fig. 1).

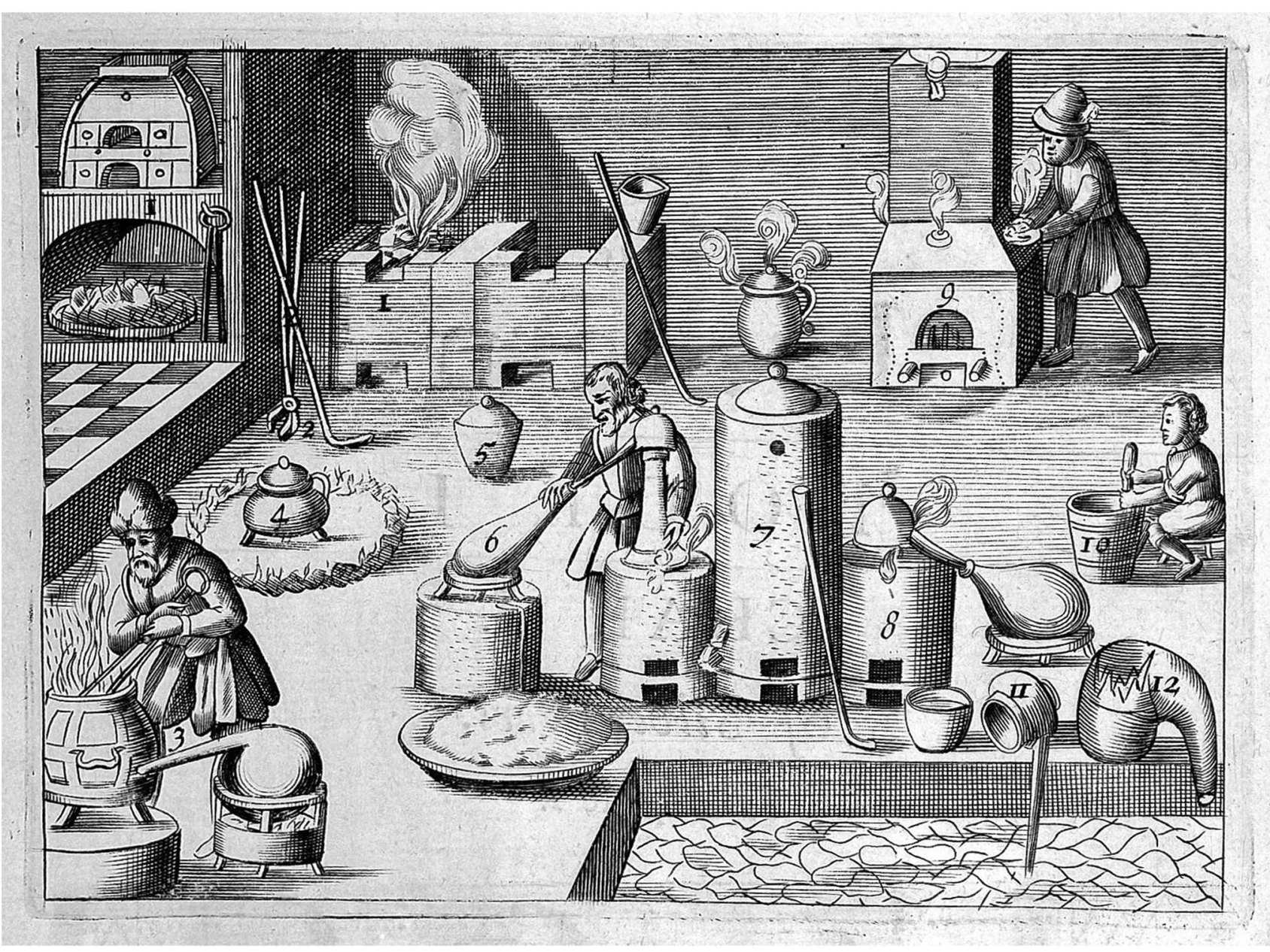

Fig. 1 The assaying workspace, from Ercker's Beschreibung of 1574. Wellcome Library, London 
At the same time, alchemy was slowly changing into chemistry (or as some historians prefer to call it in this period, chymistry). One of the first chymists was the German physician Andreas Libavius who published Alchymia in 1597 with the aim of separating chymistry from the more contentious alchemy. Nine years later he added an appendix to the second edition which outlined the concept of a chemical house in deliberate contrast to Tycho Brahe's astronomical castle at Uraniborg. Libavius saw his chemical house as being integrated into the town and hence in the public sphere in opposition to what he saw as the aristocratic isolation of Uraniborg. In that sense, his chemical house was perhaps one of the earliest attacks on the "ivory tower" model of research.

While Libavius's chemical house was a rhetorical device and although it would have been impractical if it had ever been built as it lacked good ventilation, it was a masterplan for a well-designed chemical laboratory building. The house was the residence of the chemist and his assistant, an arrangement which became traditional in German academic chemistry up to the twentieth century. The chemist's private laboratory was linked directly to his study and living quarters, just as in the nineteenth century's professorial residence. The most important aspect of the chemical house's interior is the side rooms; it is not just a single-room laboratory. There were several store rooms, including a general store for chemicals and apparatus. Even more striking are the rooms set aside for specific operations such as the analytical laboratory with its assay furnaces and balances in cases, the coagulatotorium (the crystallisation room with its tubs and vats and a table for vessels), a preparation room and a pharmacy for the making of medicines. Around the walls, specialised furnaces were placed in a precise arrangement: the steam bath and ash bath were near the entrance, followed by the water bath, the apparatus for upwards distillation and the sublimation apparatus. On the other side of the hearth were a reverberatory furnace, the ordinary distillation apparatus and the distillation apparatus with a spiral condenser. The dung bath was placed discreetly near the main entrance (Figs. 2, 3).

It is hard to tell how much influence this chemical house had on laboratory design during the seventeenth century. The laboratory at Altdorf, near Nürnberg, in 1682 was rather similar with different furnaces arranged round the
Fig. 2 Libavius's ideal laboratory from the rear, 1606 Courtesy Oesper Collections, University of Cincinnati

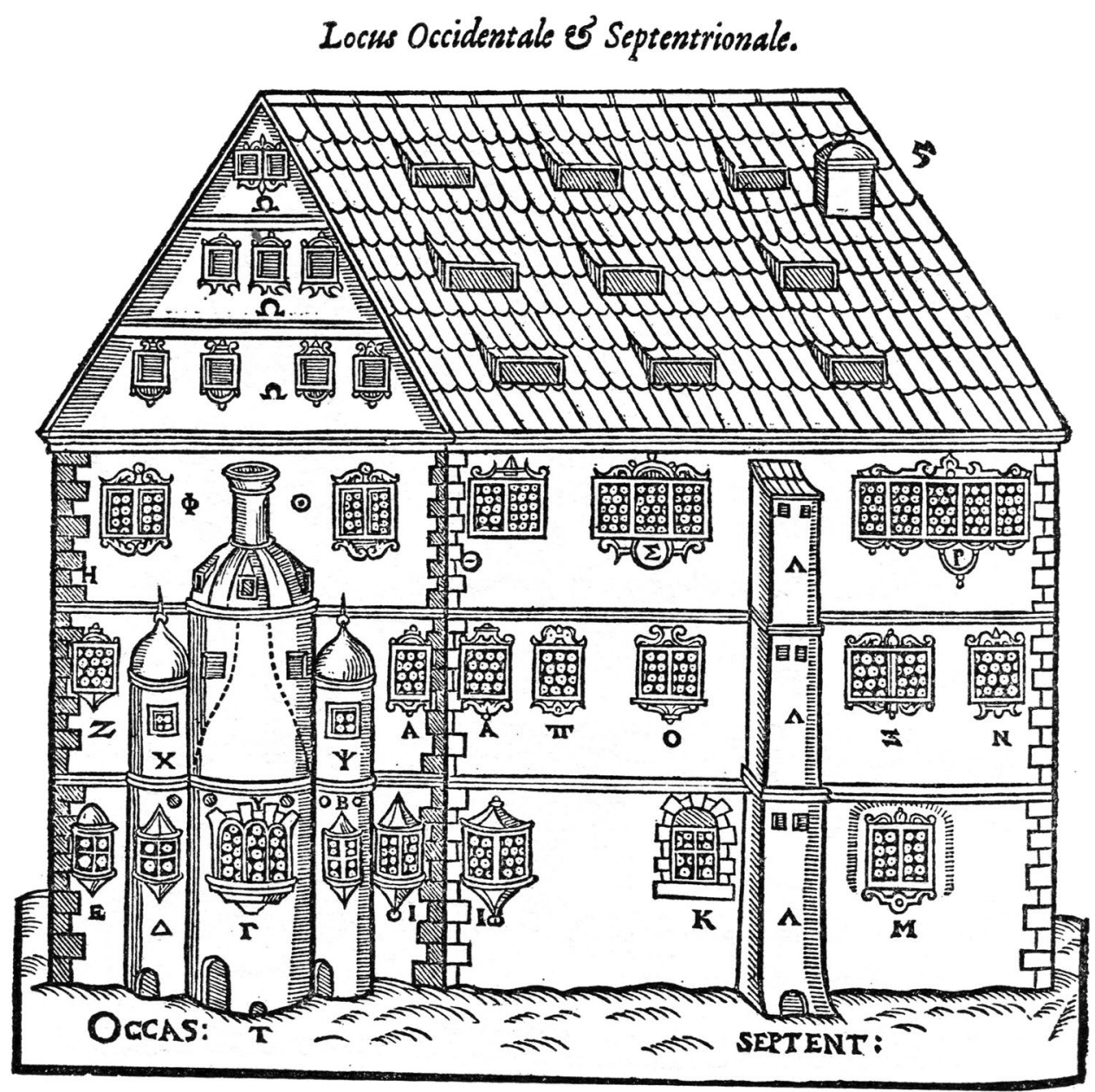




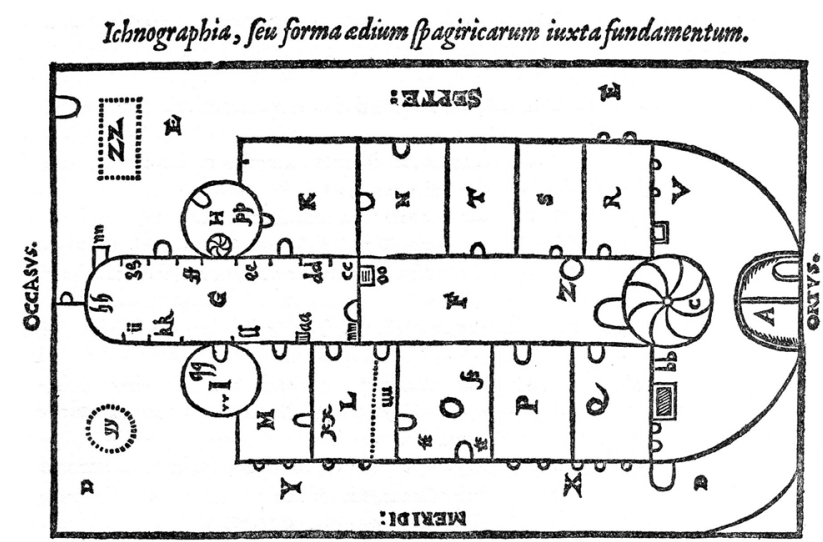

Fig. 3 Plan of Libavius's ideal laboratory, 1606. Courtesy Oesper Collections, University of Cincinnati

walls in a specific order with spaces between them rather than being adjoined together (Fig. 4). The chemical house was not designed for teaching so it lacks the central table for students taking notes. A table or tables in the centre would have been a logical feature of Libavius's laboratory but would not have featured on a ground plan. This raises the issue of the worktop used for practical work. The metallurgical workplaces of Agricola and Ercker lacked such working surfaces, at least in the idealised drawings that appeared in their books. Operations appeared to have been carried out on the ground. In the Leipzig laboratory of 1638 , the main furnace in the centre of the room also served as a worktop.

\section{Discussion points:}

- How did the chemical laboratory begin: was it a real change or just a semantic distinction?

- As it was never built, what relevance does Libavius's "chemical house" have to the history of the chemical laboratory?

- In what way is the early history of the chemistry laboratory relevant to our understanding of the modern chemistry laboratory?

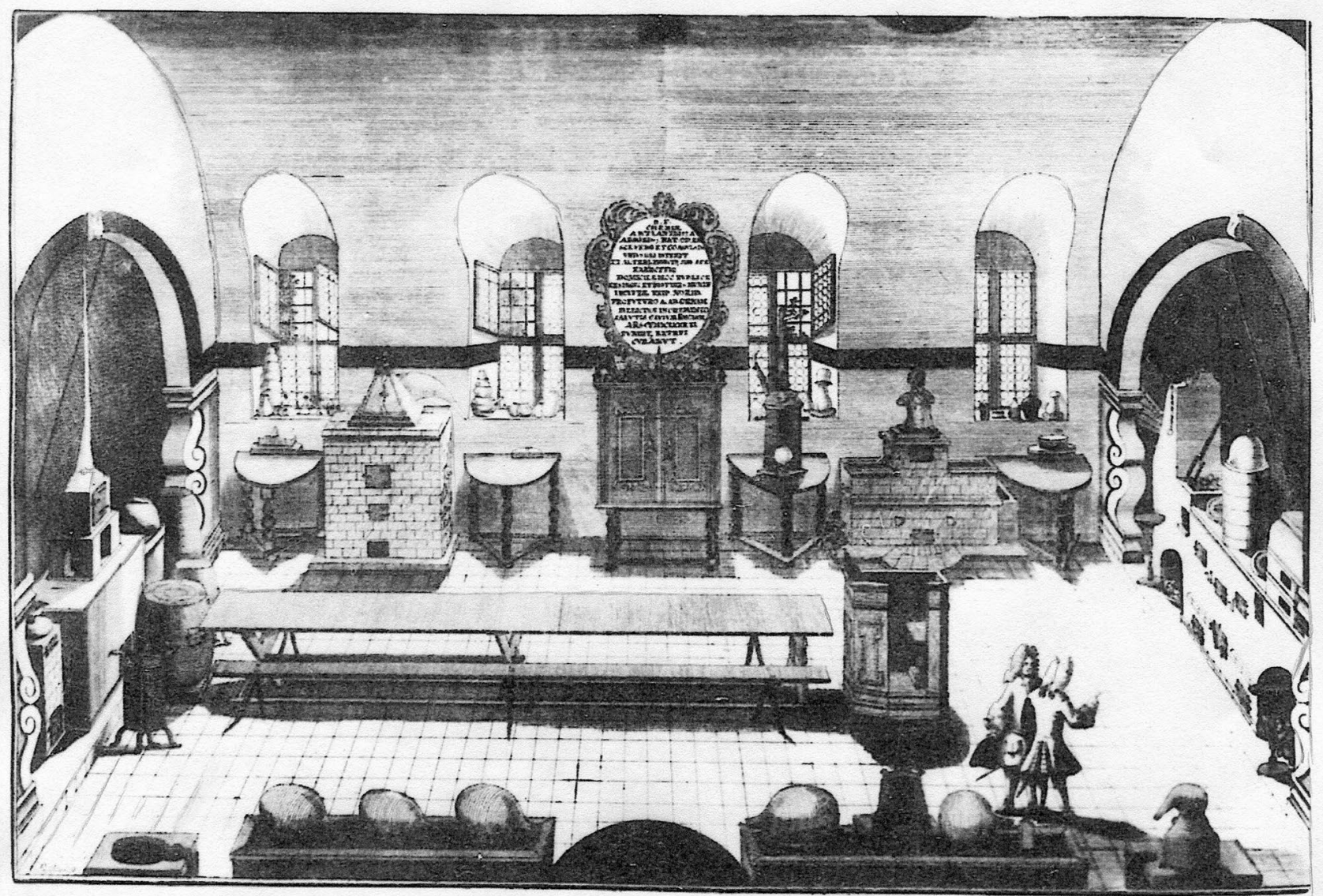

Fig. 4 Laboratory and lecture room at the University of Altdorf, 1682. Courtesy Oesper Collections, University of Cincinnati 


\section{The early development of the laboratory}

Heat was the central operation of alchemy and early chemistry, used to break materials down, to distil liquids and to speed up reactions. As we have seen, heat was provided in several different ways, but the main furnace dominated the laboratory to an extent we now find difficult to grasp. The furnace not only provided heat for chemical operations but also heated the laboratory. By the same token, the laboratory must have been uncomfortably hot in the summer. A visitor to a laboratory could quickly judge how well the laboratory was managed by the state of the furnace. The glassware was also largely the same as in the alchemical workshop with retorts and alembics for distillation.

However, with the development of pneumatic (gas) chemistry in the eighteenth century, the equipment in the laboratory began to change. Instead of a large furnace and alembics, the chemist now needed a water-filled trough to collect gases and somewhere to place the glass apparatus to prepare and manipulate gases. The smaller scale of this new style of chemistry made it possible to carry out experiments in a domestic setting and even on a tea tray. This seems to have been the British approach to these changes.

By contrast, the French retained the laboratory but the room was now dominated by large tables for chemical operations. Although the new pneumatic chemistry did not require a large source of heat (Lavoisier and Priestley [introduced below] for example used a burning glass to supply the necessary heat), a furnace could be placed in a corner or along one wall. It was even possible to put small portable furnaces on the table. This arrangement can be seen in the illustration of a laboratory in the Diderot's Encyclopédie of 1780 and the English clergyman Joseph Priestley had a similar laboratory in Northumberland, Pennsylvania, at the end of the eighteenth century. Priestley's French rival, the French tax-collector Antoine Lavoisier, had a laboratory in which the furnace was notable by its absence and the room was dominated by storage space for glassware and a large pneumatic trough, essentially a water bath with legs (Fig. 5).

Lavoisier came to chemistry from physics and geology, and he was probably influenced by the then popular cabinet de physique. This was a room containing shelves of physical apparatus and a central table for experiments or perhaps more often demonstrations to visitors. The French priest and natural philospher Jean-Antoine Nollet's cabinet resembled Lavoisier's laboratory in many respects. The famous Swedish chemist of the early nineteenth century, Jöns Jacob Berzelius, carried out his chemical work on two ordinary kitchen tables, one for himself and one for his assistant. The closest example to Lavoisier's laboratory

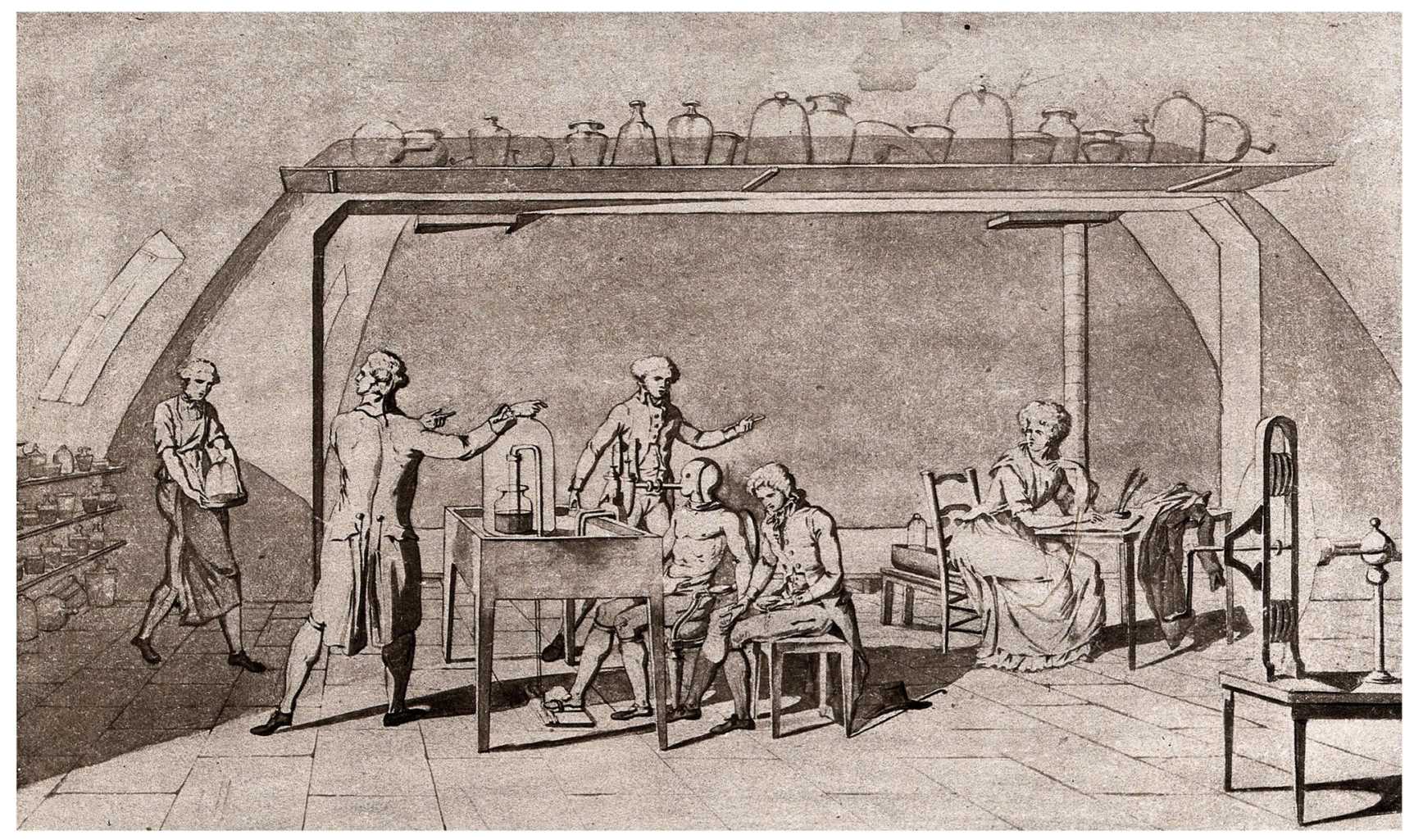

Fig. 5 A view of Antoine Lavoisier's laboratory in the Paris Arsenal, c. 1790. Wellcome Library, London 
in the early nineteenth century was the laboratory at the University of Leiden in 1831 which not only had the table, but also a similar pneumatic trough on legs. The preference of French chemists for laboratory tables over laboratory benches continued in the nineteenth century with both Louis Pasteur and Marcellin Berthelot using tables for their experiments. It is not insignificant that Pasteur was both a chemist and a microbiologist and Berthelot was a physical chemist, as both microbiology (and the later biochemistry) and physical chemistry laboratories tend even today to have tables rather than chemical benches.

For all these changes, the traditional chemical laboratory with its main furnace and assembled glassware survived until the early nineteenth century. A good example is the technical chemistry laboratory at Leiden in 1831 . The English physician William Lewis's laboratory at Kingston-upon-Thames in the 1750s (Fig. 6) and the English instrument-maker William Haseldine Pepys' laboratory at the London Institution in 1819 were also traditional in design. Before this style of laboratory which, in many respects, went back to the medieval alchemists, could disappear, piped gas and water had to be introduced.

\section{Discussion points:}

-Why was the furnace so important in chemistry before 1850 ?

- Is a bench necessary for chemical work or would tables suffice?

-Is the laboratory bench distinctive to chemistry?

\section{Laboratories in education}

In the last section, we saw how the evolving nature of chemistry changed the fittings of the laboratory, but also how technological advances were necessary before the traditional furnace-centred laboratory could be abandoned. Clearly much depends on what type of chemistry is being done in a laboratory: in other words form follows function. As teaching is one of the main functions of the chemical laboratory even today, we have to consider the origins of the teaching laboratory, which lay in lecture demonstrations by a teacher, usually with the help of an assistant. One of the earliest illustrations of a lecture demonstration shows the French medicinal alchemist Annibal Barlet

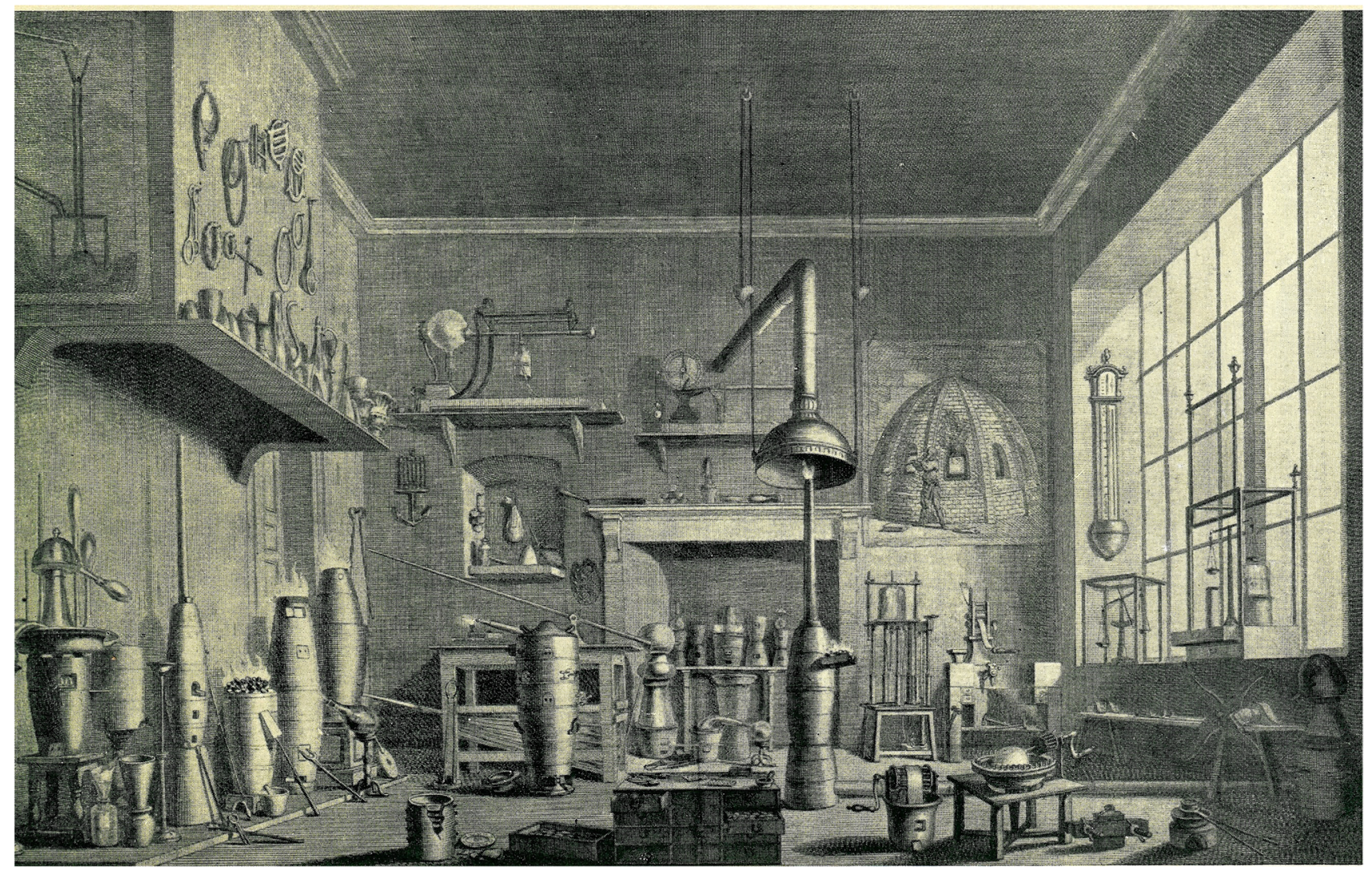

Fig. 6 William Lewis's Laboratory, Kingston, Surrey, 1763. Courtesy Oesper Collections, University of Cincinnati 
teaching in mid-seventeenth century Paris. These pictures show three key elements of the lecture-demonstration: the use of a long table for the demonstrations, an assistant to help with the demonstrations and the use of specialised equipment. Equipment suitable for lecture-demonstrations has to be of suitable scale for use on the table. While Barlet is carrying out the lecture-demonstration in a specific lecture space, this is just an extension of his laboratory and materials for the lecture were presumably brought from the laboratory area by the assistant. So this raises the question, is the space a laboratory or a lecture hall? (Fig. 7).

Surprising as it may seem now, the separation of the lecture theatre from the laboratory was not completed until the mid-nineteenth century. For much of this period, the laboratory, even if it was separate, was used mainly for the preparation of lecture-demonstrations rather than practical instruction or research. Lecture-demonstrations were very important in chemistry teaching right up to the midtwentieth century. During the eighteenth and early nineteenth century, lecture-demonstrations were the preeminent way of teaching and professors such as the Scotitsh physician Joseph Black were famous for their impeccable lecture-demonstrations rather than their research. Hence, the laboratory was actually part of the lecturing space or adjacent to it. At the University of Altdorf in 1682, the students sat at a long table in the middle of the laboratory (which as we have seen was similar to Libavius's chemical house) underneath a pulpit from which the professor lectured. American chemist Robert Hare's lecture theatre at the University of Pennsylvania medical school in the 1830s had a long lecture bench for the demonstrations with a fully equipped laboratory in the space back-stage behind the bench. Crucially this laboratory was used between lectures for experimental work (Fig. 8).

The next step was to partly separate the laboratory from the lecture hall. This arrangement existed in London's privately funded Royal Institution from 1804 onwards. There is an archway between the laboratory and the lecture space with a lecture bench in the middle of the archway. The fairly simple laboratory with shelves on the walls for chemicals, cupboards for apparatus, a furnace and a large sandbath served as a preparation laboratory for the lectures, but was also used by the English chemists Humphry Davy and his successor Michael Faraday for their pioneering research. From the 1840s onwards, the emphasis moved towards practical instruction for the students and the use of laboratories for research. Hence, the introduction of large teaching laboratories and smaller research laboratories by the 1860s. The lecture hall laboratory shrank in size and became a preparation room. It was connected to the lecture hall by a connecting door or even a connecting corridor as in the case of the Bavarian Academy of Sciences in Munich in the 1850s (Fig. 9).

\section{Discussion points:}

-Why was the lecture-demonstration so important for the teaching of chemistry?

-Why did the laboratory become separated from the lecture hall and become simply a prepararation room? -What is the best way to teach chemistry?

\section{The birth of the classical laboratory}

In the 1860 s, a revolution in laboratory design took place. A new type of laboratory arrived on the scene, at first in a few German universities and then across the world by the end of the century. Essentially this is the chemistry laboratory that we all know today. It consisted (and in many places still consists) of rows of wooden benches with bottle racks above the benches and drawers and storage cupboards underneath the benches. The benches were all fitted with piped gas and running water. There were washbasins at the end of the bench and eventually in the bench itself at regular intervals. There was a drainage system to take all the liquid waste to mains sewage. There were fume cupboards (also called fume hoods) along the walls, at least along the outer wall. The benches were arranged in two rows with a wide aisle between them like a hospital ward. These laboratories were fitted with forced ventilation, not least because many of the operations that would now be confined to the fume cupboard were carried out on the open bench (and this remained the case within the lifetime of the author) (Fig. 10).

This classical laboratory as I call it had its origins in the previous 2 decades. Liebig's laboratory at the University of Giessen in the early 1840s had benches, bottle racks and a few fume cupboards, but the overall design was different from the laboratories of the 1860s and it was on a relatively small scale (Fig. 11). The Giessen model was expanded in the Birkbeck Laboratory of University College London in 1846; with an adjoining lecture space it also had similarities to the laboratory at the Royal Institution. The crucial step toward the development of the classical laboratory was taken at Heidelberg in Robert Bunsen's new laboratory in the late 1850 s with the introduction of piped gas and water (and even direct-current electricity from a central battery). The introduction of these utilities made possible the development of the Bunsen burner as the main source of heat-thus removing the need for a chemical furnace-and the introduction of the water-powered filter (or aspirator) pump, which is synonymous with harvesting crystals. However, Bunsen adopted a relatively simple laboratory design. The fullblown classical laboratory building in all its glory had 


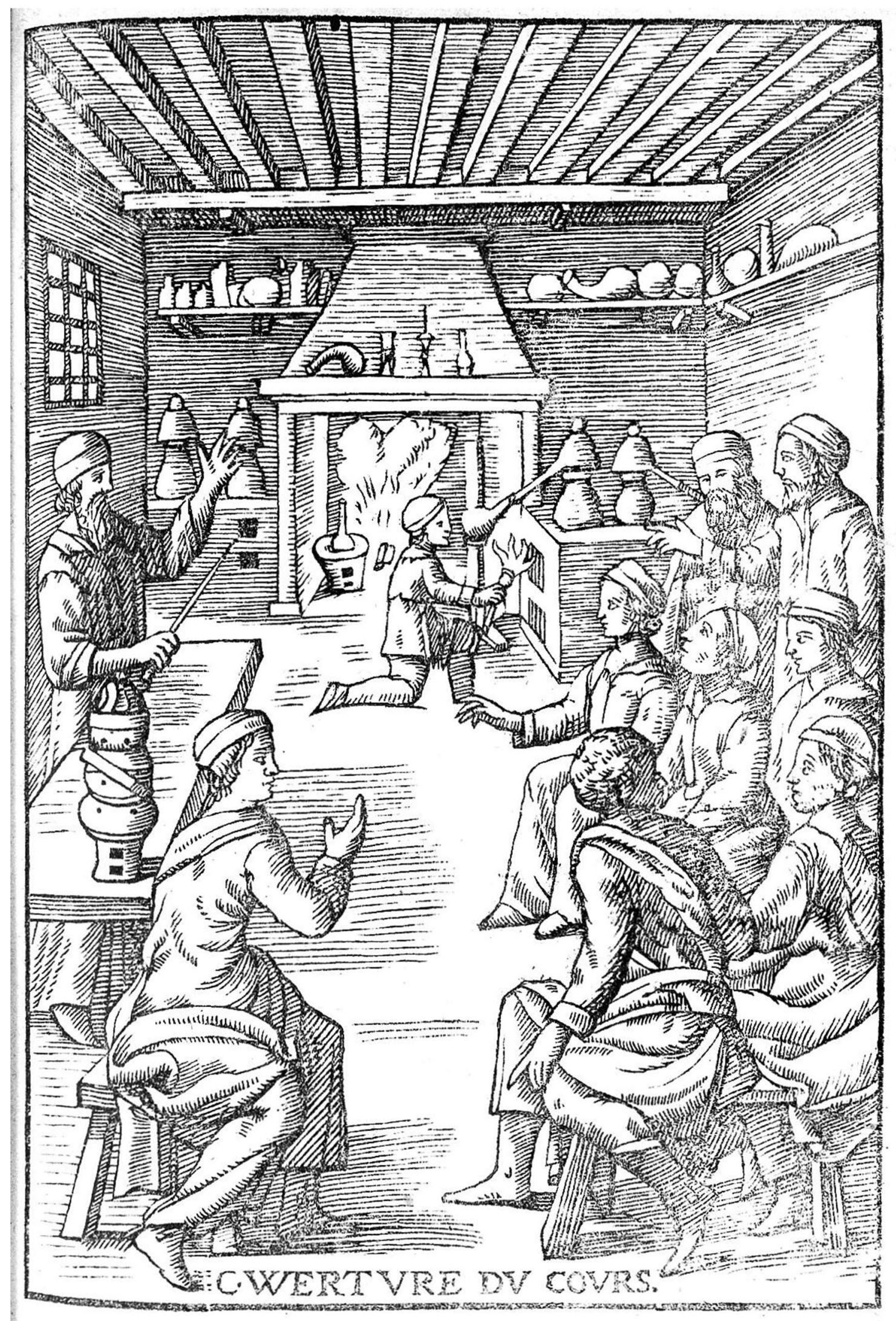

Fig. 7 Annibal Barlet lecturing in his laboratory, 1657. Wellcome Library, London 


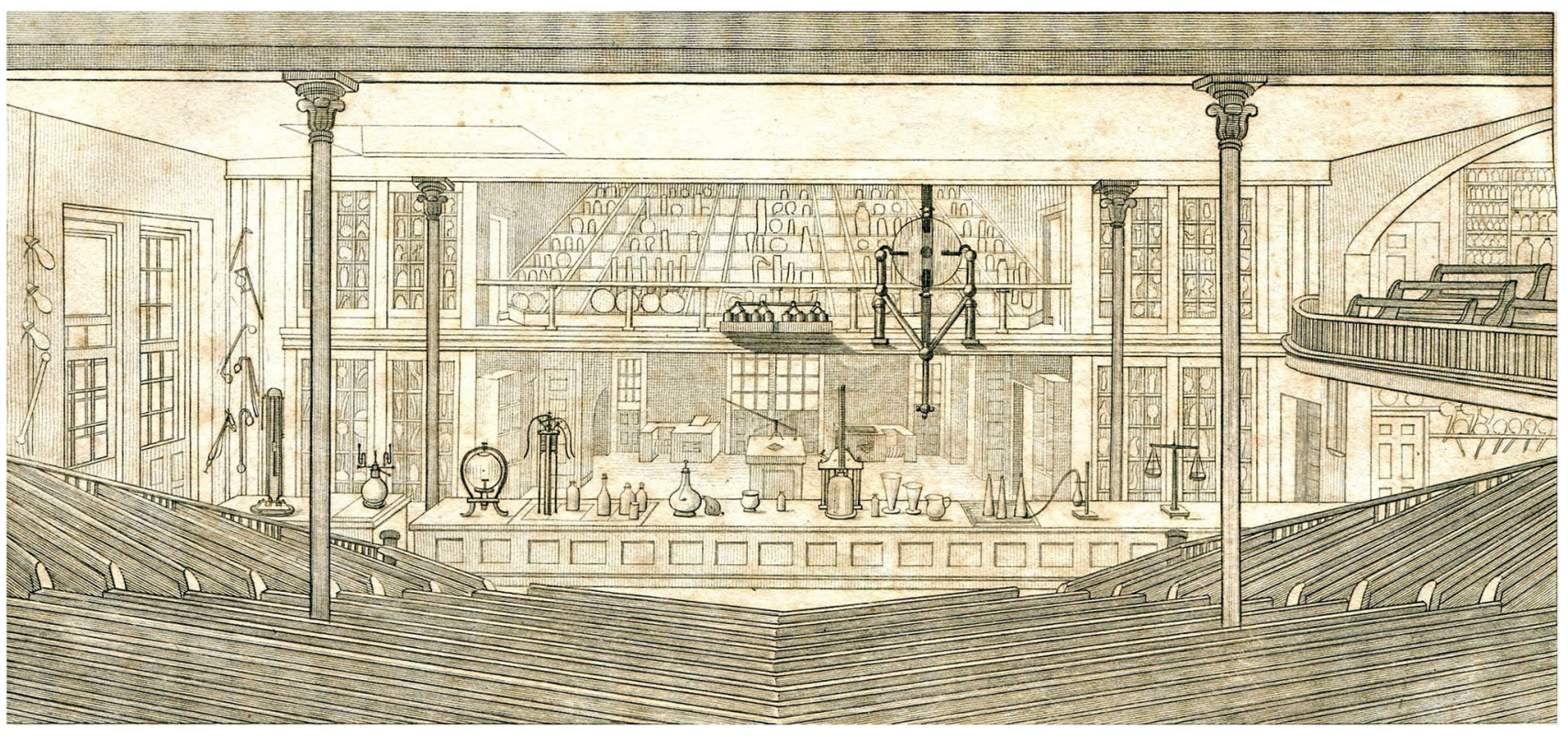

Fig. 8 Robert Hare's laboratory and lecture hall at the University of Pennsylvania Medical School, circa 1830. Courtesy Oesper Collections, University of Cincinnati

to await the building of large new buildings by Wilhelm Hofmann in both Berlin and Bonn and by Hermann Kolbe in Leipzig in the 1860s. However, these fine buildings may have not been the very first classical laboratoriesHofmann drew much of his design from an earlier laboratory at the relatively minor university at Greifswald.

This laboratory design did not displace all other designs immediately. In the nineteenth century, new laboratories were only constructed once a generation, usually with the arrival of a new professor. German ideas were not popular in France after the Franco-Prussian War and the Sorbonne only introduced the classical laboratory in the 1890s. Spain, Portugal and Italy were also slow to take it up, often preferring the tabletop laboratory which was favoured in France between the 1840s and 1880s. Owens College Manchester (later Manchester University) in the 1870s preferred the simpler Heidelberg design thanks to Henry Enfield Roscoe's close relationship with Bunsen. That the classical design did eventually succeed owed much to the energy and diplomacy of Hofmann who promoted its use across the globe. When the Sorbonne adopted this style in the 1890s, the now elderly Hofmann was their main advisor. In the USA, however, they used a slightly different design, which often had peninsula benches (benches arranged in one row to one side rather than two central rows) and removable metal bottle racks or no bottle racks at all.

\section{Discussion points:}

-Why did the "classical" laboratory eventually displace other kinds of chemical laboratories?

-Why did the classical design survive for so long?

-Was the difference between the teaching laboratory and the research laboratory simply a matter of size?

\section{The chemical palace}

This new laboratory was only part of the revolution in laboratory design. Hitherto, the laboratory had been just that, a single room (or two) attached to a lecture theatre and perhaps the professor's accommodation. In the 1850 s and 1860 s, a number of laboratories —of different sizes-were brought together in a large laboratory building which contained a number of other rooms. This was truly an impressive chemical palace, especially in Bonn and Leipzig (Berlin had a more cramped site), and was widely emulated by the end of the century. There would be undergraduate teaching laboratories, laboratories for research students and a smaller research laboratory for the professor. There would be at least one and probably two lecture theatres with the associated preparation room for setting up lecture demonstrations and also smaller classrooms (called recitation rooms in America). There would be small rooms for specific purposes such as the combustion analysis room (Fig. 12) and the darkroom for 


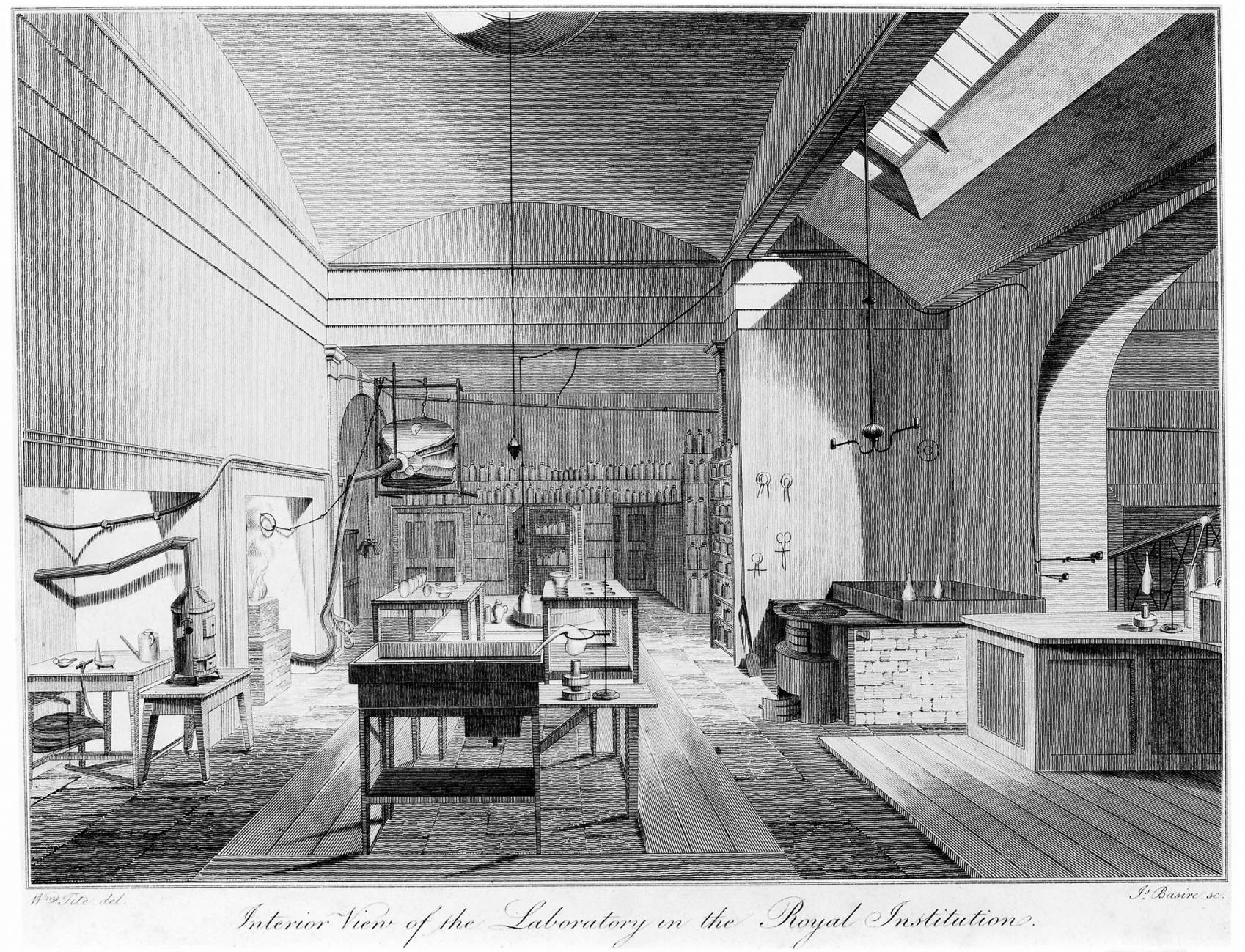

Fig. 9 Royal Institution Laboratory and lecture room, 1819; the sand bath on the right was moved to the middle of the laboratory around that time. Courtesy Oesper Collections, University of Cincinnati

spectroscopy and developing of photographs. There would be specially designed rooms for using hydrogen sulphide (the Stinkzimmer) and explosive reactions. Dangerous experiments were often carried out on balconies designed for the purpose (as in the case of the Normal School in South Kensington, London, in 1872) or on the roof. There would be a store room for chemicals and apparatus and the associated workroom for laboratory technicians. The basement would be given over to large equipment such as boilers, the central battery and eventually generators. There would be a library which probably grew out of the professor's personal library but became by the late nineteenth century available at least to the research workers. Eventually there would even be rooms for secretaries and financial staff. Finally, in German universities at least, the director of the laboratory building (the chemical institute as the Germans called it), who was usually the most senior professor if there was more than one, was expected to live on the premises. Hence, these new chemical palaces often contained lavish living quarters for the director. Hofmann's residence in the Berlin laboratory building even had a ballroom, but characteristically Bunsen's bachelor accommodation in Heidelberg was modest in style.

Many of these specialised rooms still exist in modern laboratory buildings, but one in particular has almost completely disappeared, namely the chemical museum. The chemical museum was not a science museum in the modern sense of the word and was not at all historical except accidently as the exhibits aged. They were more like modern geological or natural history museums with their scientific specimens. The first chemical museum was set up in Uppsala, Sweden, in 1769 , but there were only a few museums in existence before 1850 after which they were to be found in many of the new laboratory buildings constructed in the second half of the nineteenth century. Their collections had three different strands and the degree to which one of these 
Fig. 10 Chemical laboratory, Eidgenossische Technische Hochschule, Zurich, 1905. Wellcome Library, London
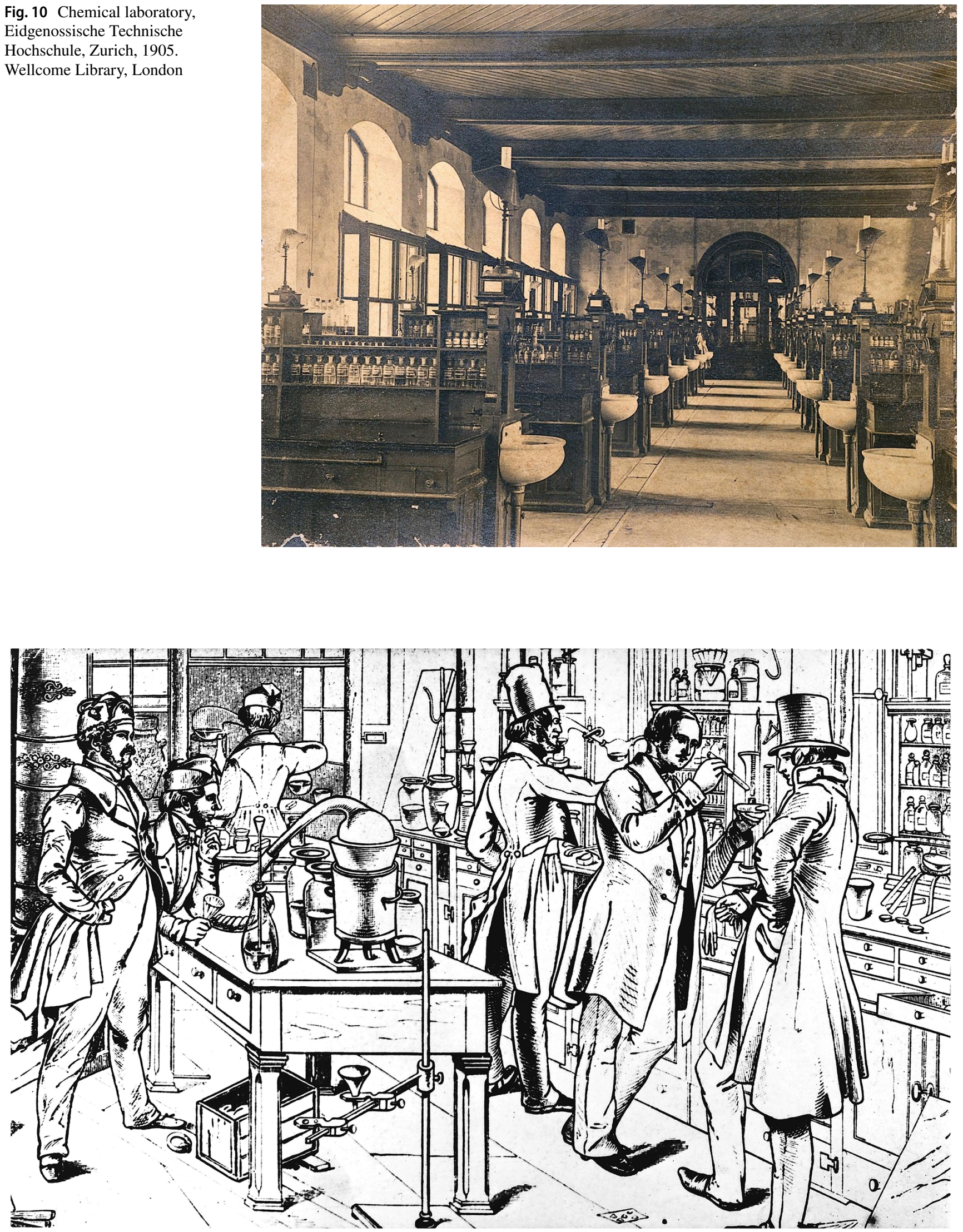

Fig. 11 Wilhelm Trautschold's engraving of the new laboratory at Giessen, 1842. Wellcome Library, London 
Fig. 12 Combustion analysis room, Eidgenossische Technische Hochschule, Zurich, 1905. Wellcome Library, London

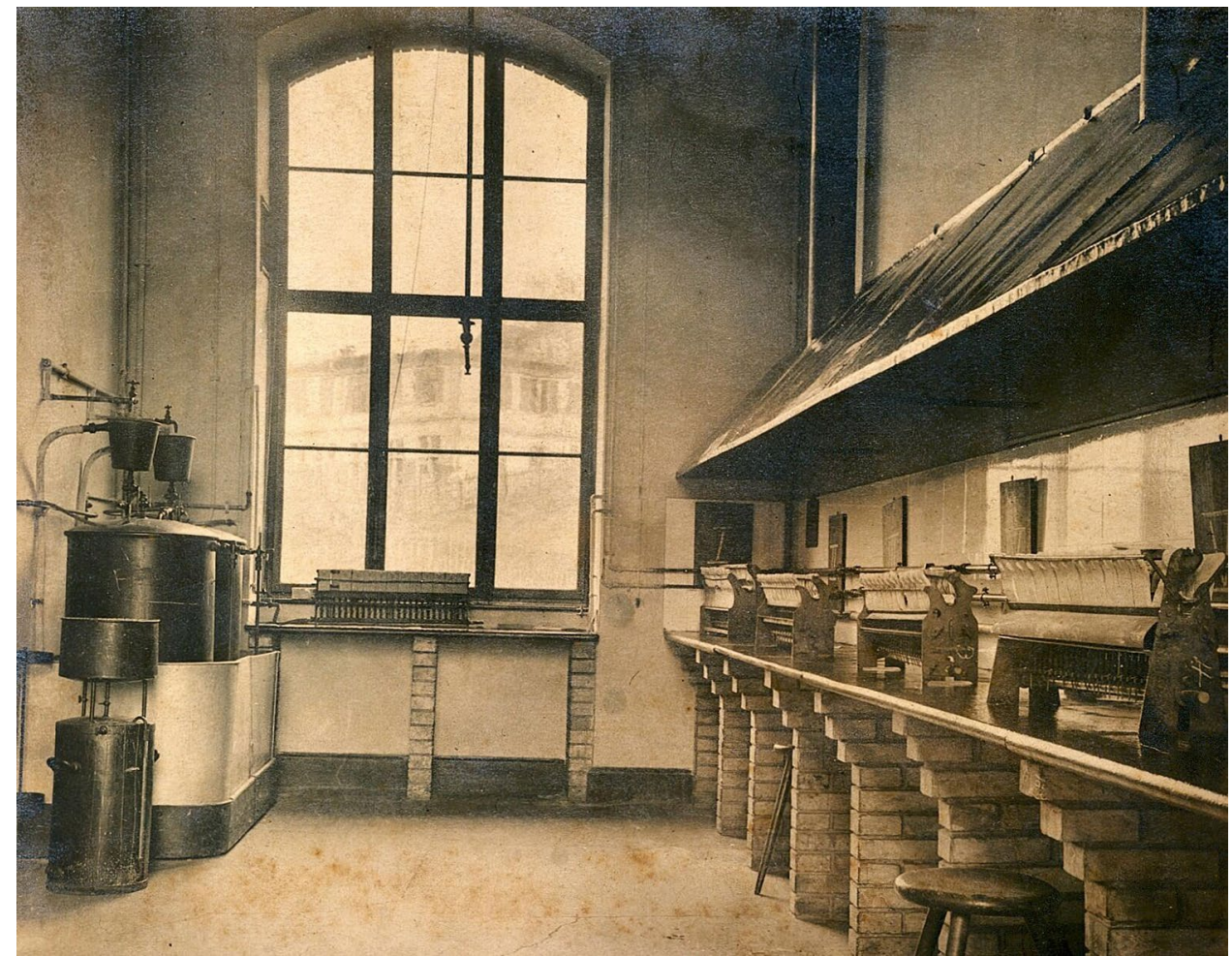

strands predominated depended on the origins and institutional setting of the museum. They contained chemical specimens made in the laboratory which could then act as reference specimens for later samples. However, this was a relatively unimportant aspect of most of these museums. They could also contain samples of chemicals and finished products from companies eager to promote themselves to the chemistry students in that particular laboratory. Indeed, several museums were set up to accommodate these donations. Conversely the professor might actually go out and obtain these samples from a range of companies and even make trips abroad for this purpose. However, the most important purpose of many of these museums was as a repository for items displayed in lectures or shown to the students after the lectures. For that reason the collection was sometimes stored in the lecture theatre or in a store cupboard near the lecture theatre. By contrast, some of these museums were elaborate affairs with the exhibits displayed in showcases in a large room. Charles F. Chandler created such a museum at Columbia University in New York City and his brother William H. Chandler at Lehigh University in Bethlehem, Pennsylvania (Fig. 13). There was also a major museum of applied chemistry at the Imperial University in Tokyo (now Tokyo University). Chemical museums were still being set up in the earlier part of the twentieth century, but the last one known to the author was founded at Brooklyn Polytechnic Institute, New York, in 1932 despite the fact that a manual of laboratory design mentioned them as late as 1951. From the 1950s, their original didactic purpose seemed to have been lost and, if they were retained at all, the museums were relocated to the entrance foyer of the laboratory building as a historical curiosity. The only chemical museum in anything like its original setting is at Edinburgh University, largely as a backdrop for the departmental coffee room.

\section{Discussion points:}

- In what ways was the development of the large chemistry building a more significant change in chemical practice than the actual laboratory design and in what ways was it not

- In what way is the fume cupboard a distinctive feature of chemistry laboratories?

- Why do you think chemical museums have largely disappeared?

\section{Social structure of the laboratory}

Until the nineteenth century, there were few people in the laboratory, usually just the chemist and his assistant, and the issue of social organisation did not arise. As the number of students (or researchers) in a laboratory increased and the number of support staff also grew, a social hierarchy quickly developed. This hierarchy varied between different 
Fig. 13 Chemical museum at Lehigh University, 1893. Courtesy Oesper Collections, University of Cincinnati

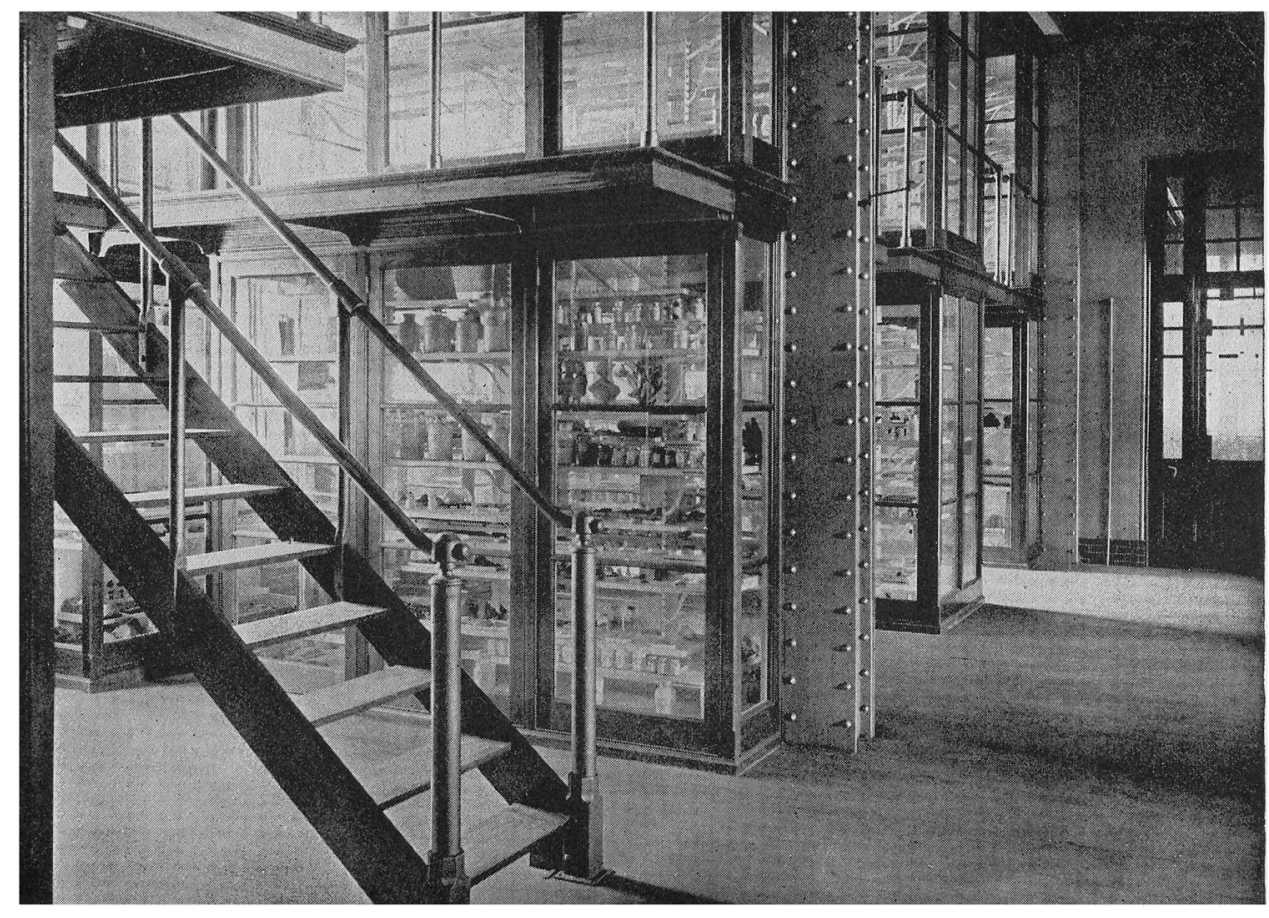

countries - the situation in England was dissimilar to that in Germany. There was always a head of the laboratory building (called a chemical institute in German academia), with a deputy or deputies if the laboratory building was large enough. Under this director, there would be heads of individual laboratories (or departments). The next rank down would be individual researchers or lecturers in academia. The bottom ranks in academia were the demonstrators who supervised the students in the laboratory.

There was also a hierarchy on the service side of the laboratory as well. At the top, there was a superintendent who carried out the day-to-day management of the laboratory. Initially, the routine work in the laboratory was carried out by the laboratory assistants or even more lowly laboratory servants (called Dieners in German). The laboratory servants were from the working class and were sometimes retired military men. They were usually completely untrained in chemistry and learnt their craft on the job. After the First World War, the laboratory servant was replaced by the laboratory technician (Laborant in German). They were better trained, either taking a chemistry qualification before being appointed or undergoing part-time education (such as evening classes) while being employed. As laboratory buildings continued to expand, the number of specialised staff also grew. There would be a librarian, curators, secretaries and cleaners. When more complex instrumentation arrived in the 1950s, they were usually under the supervision of a specialised instrumental technician and sometimes even a technician for each type of instrument, such as nuclear magnetic resonance spectrometer or a mass spectrometer.

The situation described mainly applies to the academic laboratory building, but a similar system existed in industry, especially in the research laboratories. There was (and is) a hierarchical structure in which the chemists in the research laboratories are superior to the chemists in the works laboratories (see below) and the works chemists are in turn above the process workers. Furthermore, the works laboratories often employ junior laboratory staff, who are positioned in the hierarchy between the works chemists and the process workers to carry out routine analyses. These social distinctions were often made clear by different coloured laboratory coats or overalls. For example, the research chemists will wear white laboratory coats, the lower chemists brown coats and the workers will have blue overalls.

\section{Discussion points:}

- Can a social hierarchy in the chemistry laboratory serve a useful purpose?

- In what ways does a marked social hierarchy make the laboratory safer or more dangerous?

- To what extent do modern laboratories still have a hierarchy? 


\section{The industrial laboratory}

The first industrial research laboratories were set up in the 1860s in France and were soon followed by large laboratories in the Germany dye industry from the 1870 s onwards. The style of these laboratories varied from company to company and probably even within companies. The research laboratories of BASF in Ludwigshafen were closely modelled on their academic counterparts, while the laboratory that the dye firm Bayer established in 1891 was rather utilitarian with more of a feeling of an industrial building. This was then followed by a pharmaceutical research laboratory as Bayer began to diversify from dyes to pharmaceuticals. These laboratories developed new products for the company and hence were seen as securing the firm's future. By the 1920s, pretty well every chemical or pharmaceutical company had a research laboratory of some kind.

However, they were not the only laboratories in the chemical industry, although most academic studies have been limited to the study of industrial research. Small works laboratories were more numerous (as each individual section of a factory would have its own laboratory) and they have a long lineage. Indeed, if we consider the metal refining industry to be part of the chemical industry, these laboratories can be traced back to the workplaces portrayed by Agricola and Ercker in the mid-sixteenth century which carried out activities such as assaying. In a similar manner, most pharmacists (the so-called compounding pharmacists) would have had a back shop which served partly as a laboratory and partly as a small manufactory for drugs. In many respects these pharmaceutical workshops were similar to contemporary chemical laboratories. A rather grand example of such a laboratory-workshop was the laboratory of the Society of Apothecaries at Apothecaries' Hall in London founded in 1672. Following developments in the late eighteenth and early nineteenth centuries, a Great Laboratory was constructed in 1822-1823. Its main purpose was the manufacture of drugs for the Royal Navy and the East India Company, but it also carried out chemical operations such as analysis.

Most of the works laboratories in the chemical industry and other related industries such as brewing were small and poorly equipped. At best they would be fitted with gas and running water by the end of the nineteenth century, but this was by no means certain even in the twentieth century. They were usually adjuncts to a particular process plant in the factory and were just small brick rooms or even sheds. In addition to routine analysis of the incoming raw materials and the products produced by the plant using procedures laid down by the national pharmacopeia in the pharmaceutical industry, they would attempt to resolve process problems in the plant on an ad hoc basis. The chemists occupying these laboratories would often have just a basic grounding in chemistry, perhaps acquired in evening classes or just on the job. Such laboratories had a higher status in the larger firms in the German dye industry where highly qualified chemists who had developed a process would move to the works laboratory to erect and operate the process plant rather than handing this task over to a chemical engineer or a works chemist. Indeed, such laboratories, for example the Indigo Laboratory at BASF, even had their own research programmes.

\section{Discussion points:}

-What are the differences between academic and industrial laboratories?

- Why are works laboratories usually overlooked by historians?

- To what extent do all chemical and pharmaceutical companies need research and development laboratories or should they leave R\&D to the largest firms?

\section{The school laboratory}

The school laboratory is where most of us first came across a chemistry laboratory when we reached secondary school (primary schools do not usually have such laboratories) and indeed, for many people, it may be their only contact with a chemistry laboratory. Yet at first sight a school laboratory seems a strange concept: why would a school have something as dangerous as a chemistry laboratory? This is partly because the obvious risks-naked flames, reactive metals, flammable liquids, carcinogenic solvents, poisonous gases and asbestos-were to a large extent disregarded in the nineteenth century and even to a large extent up to the 1960s.

That schools did have laboratories was the result of the belief-widespread by the late nineteenth century-that chemistry could only be taught through practical instruction. Chemistry could only be learnt through doing chemistry in the form of routine exercises, rather like a kind of intellectual calisthenics. Initially, in the earlier part of the nineteenth century, science had been taught insofar as it was taught at all in the form of the lecture demonstration in common with other teaching institutions. As these lecture demonstrations were often fairly simple, they did not require a laboratory. However, in the middle of the nineteenth century, there were three major changes which together more or less compelled the construction of school laboratories. The state began to provide education for the general population rather than (or least in addition to) the church or private fee-paying 
institution, thus greatly increasing the number of schools. A system of examinations was introduced to test children at specific stages in their education. The educational syllabus was broadened beyond the time-honoured curriculum of Latin, Greek and mathematics to modern subjects such as geography and history, and crucially, the sciences. Given the general belief that chemistry should be taught in the form of practical exercises, some kind of school laboratory thus became essential.

Regarding their general form, they tended to copy the classical design or its earlier variants at Giessen and Heidelberg, but perhaps in a simplified form, for example without the bottle racks or by using tables rather than benches (and lowering the height of the benches). However, the need for gas for the inevitable Bunsen burner (with its asbestos mat to protect the wooden bench) and running water favoured the bench over the simpler tables. That said, the simple spirit lamp found in most chemistry sets offered a rather anaemic alternative to the Bunsen burner without the need for piped gas. Fee-paying schools could afford to build laboratories similar to university laboratories (albeit with some additional fund-raising), but state schools needed grants from government to build even basic laboratories. This enabled the state (for example in England's Department of Science and Art) to lay down a standard laboratory design which had to be more or less rigidly adhered to. Starting with a handful of school laboratories in the 1870s, the Department of Science and Art had approved over a thousand by the time it became the Board of Education in 1899.

The key concept of practical instruction was that the pupils should carry out a given set of exercises to improve their experimental ability and their understanding of chemistry. The simplest and most obvious way of doing this was the qualitative analysis of unknown metal salts using what was called group analysis, because the analysis was carried out in sets of tests which identified five specific groups of chemically related metals. Various reagents were used in these tests, such aqueous ammonia, sodium carbonate and hydrochloric acid, but the most problematic (yet at the same time the most useful) of these chemicals was hydrogen sulphide, partly because it was a gas which had to be on tap so to speak, but also because hydrogen sulphide is extraordinarily poisonous. Most chemists would recognize hydrogen sulphide because of its pungent and unmistakable odour (the well-known smell of rotten eggs); however, the gas disables the sense of smell at high concentrations. Fortunately, the Dutch pharmacist Peter Kipp introduced his eponymous apparatus for generating gases as and when desired in 1844 . He had intended that it be used for generating hydrogen, but by using iron sulphide and dilute sulphuric acid, it could be used to generate hydrogen sulphide gas. So the hallmark of any school chemistry laboratory up to the 1970 s was the (usually very dirty) Kipp's apparatus in a corner of the solitary fume cupboard. By this time, it was rarely used as the old system of training through qualitative inorganic analysis had been swept away by the reforms of chemistry teaching in the late 1960s and 1970s rather than because of safety concerns.

Another set of routine exercises was the volumetric analysis of solutions of unknown concentration using standard solutions and coloured indicators using a pipette, a simple burette and a conical flask. The colour change was highlighted by putting the flask on a white glazed tile. The pipette was filled by mouth and accidental ingestion of reagents such as dilute hydrochloric acid or sodium hydroxide was not unknown. Secondary schoolchildren also carried simple inorganic and organic preparations in the open laboratory as fume cupboards were usually few in number in school laboratories. They also performed simple organic analysis (such as the Lassaigne sodium fusion test). The author remembers heating iodine and aluminium powder on a strip of asbestos paper and preparing ethyl bromide on the open bench in the early 1970s as well as getting a lump of sodium metal stuck on his finger while doing the Lassaigne test!

\section{Discussion points:}

- Why did nineteenth century chemistry professors think that children in senior school needed to do practical chemistry?

- Why did the early designers of school laboratories copy university laboratories rather than developing a child-focussed design?

- Do school pupils need to do practical chemistry or could they learn the subject from books and videos?

\section{Impact of new instrumentation on the laboratory}

It is a curious fact that the chemical laboratory up to the Second World War did not use electricity very much, outside of the obvious field of electrochemistry, except for mixing, stirring, illumination, heating and refrigeration. Even so, gas remained in use for lighting and heating. Cambridge was still using gas lighting in the chemical laboratories up to the mid1940s. The projector lamp in the lecture theatre was one of the larger consumers of electricity in the chemical laboratory in the 1920s. This all changed after the Second World War, when completely new types of instrumentation were gradually introduced into chemical laboratories, a process which was largely complete by the mid-1960s. They mainly arose in physics rather than chemistry, partly as a result of wartime 
developments such as radar, and for many years they were operated by specialist technicians rather than by chemists themselves. They were also very expensive until relative mass production made them more affordable in the 1960s. The earliest physical instruments were infrared and ultraviolet spectrometers, followed by the much larger (and more expensive) nuclear magnetic resonance (NMR) spectrometers and mass spectrometers. These instruments have had a variety of uses, but in organic chemistry they are mainly used for the determination of the structures of increasingly complex organic and bio-organic molecules. The mass spectrometer and the NMR spectrometer use heavy magnets and hence they either have to be used in the basement or specially reinforced floors need to be installed.

It might be thought that this so-called instrumental revolution radically changed the design of laboratory buildings. In practice, however, the introduction of these instruments had little impact. This is partly because the classical chemical laboratory already had specialised rooms for purposes such as atomic spectroscopy or combustion analysis, which could be repurposed or replicated for the new wave of instrumentation. These laboratory buildings also contained large basements, hitherto mostly used for power plant and storage, which could accommodate the heavy mass spectrometers. This shows the resilience of the designs introduced by Hofmann and his fellow chemists in the mid-nineteenth century. Nonetheless, there was a major expansion of academic chemistry in the 1960s, especially in the USA, and new laboratory buildings were constructed to meet this demand. An important early example was the laboratory buildings erected for the chemistry department at Stanford University in California for William S. Johnson, Carl Djerassi and Henry Taube between 1960 and 1964. Externally the buildings looked like the office buildings in the nearby Stanford Research Park, reflecting the fact that the exteriors of chemistry laboratory buildings tend to reflect the architectural Zeitgeist of the period rather than any developments in chemistry. Internally there were still individual laboratories with fume cupboards running along the internal wall and one row of benches close to the windows rather than the two rows of benches with a central aisle found in the classical laboratory. This switch in laboratory design began in the US in the 1950s and indeed can be traced back to the late nineteenth century. It was based on ergonomic principles and sought to obtain the best natural light on the benches. The rooms for the new instrumentation and other techniques such as microanalysis were mostly in the centre of the building. However, a basement had to be constructed for the mass spectrometers and an underground laboratory was built to connect the two laboratory buildings.

\section{Discussion points:}

- Why did this new instrumentation which came from physics not lead to a greater convergence of the design of chemistry and physics laboratories?

-Why could some of this new instrumentation not be used in the ordinary chemistry laboratory?

- Can you think of any changes which occurred in the chemistry laboratory itself during this period?

\section{The latest laboratories}

The second revolution in laboratory design occurred around the end of the twentieth century and it was produced by increasing requirements for improved health and safety rather than any changes in chemistry. They had their origins in laboratory buildings constructed for the pharmaceutical industry in the 1990s. The booming industry had more money to spend than the academic sector and as industrial firms had a greater concern with health and safety. One of the first universities to adopt this new design was Oxford University. The different specialties had been merged into a single department in 1996 and the new head of department, Graham Richards, decided to build a new central laboratory building for chemical research, in part to replace to the ageing organic chemistry laboratory building (called the Dyson Perrin or DP). The modern trend would have been to build it on a green field site on the outskirts of Oxford, perhaps as part of a new science park, but fortunately there was a suitable site in the existing Science Area in central Oxford opposite the DP. The new building was opened in 2004 at a

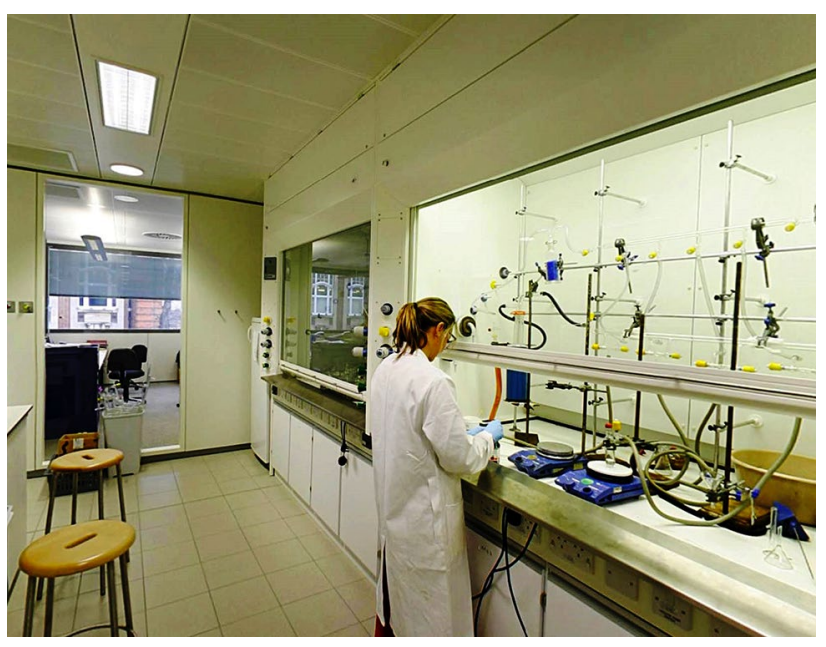

Fig. 14 Fume cupboard in the laboratory. The writing area can be seen outside, Chemistry Research Laboaratory, Oxford, 2004. Photograph by Karl Harrison, (C) University of Oxford 
cost of some $£ 60$ million, funded by an innovative mixture of government funding, venture capital and money from charitable foundations.

The new research laboratories have several new features. They are relatively small and are lined by four fume cupboards on each of the long walls, with the benches in the middle (Fig. 14). This is a far higher density of fume cupboards than in traditional laboratories. The outer wall facing onto the office space is transparent so anyone working outside can see if there is an emergency in the laboratory. The other wall opens onto a corridor which has other small rooms, each containing a piece of equipment, such as a nuclear magnetic resonance (NMR) spectrometer or a highperformance liquid chromatograph (HPLC). The researchers are now permitted to use this instrumentation because it has been automated. They just put the sample into the automatic feeder and the results are delivered to the researcher's computer electronically. While this layout brings the instrumentation to the researcher in contrast to its earlier segregation from the laboratory, the basement still contains many instruments including NMR spectrometers, mass spectrometers and semi-automated $\mathrm{x}$-ray crystallographic apparatus. The focus of this high-performance (and often huge) equipment is the study of large biomolecules rather than the small molecules which were the focus of attention a generation ago.

A key aspect of the Oxford laboratory building is the concept of dividing the space into "clean" and "dirty" areas. The "dirty" laboratory work is separated from the "clean" office areas outside the laboratories and the shared spaces such as the atrium between the office block and the laboratory block. This segregation is marked by the use of carpet for the "clean" areas and linoleum or tiles for the "dirty" areas such as the laboratories themselves and the back corridor to the instrument rooms. Even the lifts are designated as clean lifts and "dirty" lifts. There are rules about what can be done in "dirty" areas, for example, it is no longer permissible to eat or drink in the laboratories.

Another important feature of modern laboratories is the C-frame laboratory bench, which is a C-shaped steel frame (which can be on castors) from which storage cabinets can hang. This seems to have been introduced in the late 1970s and is usually made of white composite material rather than the dark colours of the traditional wooden (and heavily waxed) benches. It was recognised by the 1990s that a rationally designed chemical laboratory would have to be more flexible so that utility supplies could be easily accessed for maintenance and be much safer. In fact, the new laboratories in Oxford are so flexible (partly because of the use of the $\mathrm{C}$-frame) that they can easily be converted from organic chemistry laboratories to biochemical laboratories or even offices if need be.

\section{Discussion points:}

-Why have most laboratories retained the older design — what are the problems with renovating older laboratories?

-What other factors are involved in modern laboratory design apart from health and safety?

- Should older laboratories be demolished in the interests of health and safety (and other reasons you may have identified)?

\section{The future of the laboratory}

So what is the future of the chemical laboratory? One lesson to be drawn from this article is the remarkable stability of the chemical laboratory over the centuries. The initial form of the laboratory based on the alchemist's workshop and centred on the furnace was replaced in the nineteenth century by what I have called the classical chemical laboratory with its benches, bottle racks and fume cupboards, a design made possible by the introduction of piped gas and water. This design has been remarkably durable and despite massive changes in the nature of chemical practice in the last century and a half, it has remained the basic blueprint for most chemical laboratories.

In recent years, however, there has been an ever-growing emphasis on health and safety in the laboratory, which has already affected laboratory design and will surely continue to do so. As science becomes increasingly multi-disciplinary and integrated, the fume cupboard will surely remain as the distinctive feature of the chemical laboratories. What will be the situation in 50 years' time? If we assume that health and safety remain paramount and that there is an increasing tendency in the world at large to work at home (especially following the COVID-19 pandemic of 2020-2021, although I predicted this trend several years ago), the future may lie with robotics. Already some of the work in the laboratory, such as operating the NMR spectrometer, has been largely automated and the next step must surely be to automate the running of the experiments themselves. This has already been done to some extent in the well-funded pharmaceutical industry and is likely to continue and develop. The idea of carrying out an experiment from the comfort of your home office may seem a strange concept to many chemists, yet in principle it is not very different from operating the movement of a rover across the Martian surface from home. If one wishes to create a completely safe laboratory, the best way to do this is to remove the scientist from the laboratory. Humans often make error-prone experimentalists and they are fragile, subject to injury from exploding glassware and to poisoning by the chemicals they use. Some chemists might 
argue that remote-controlled experiments are not "real" chemistry, but an alchemist of the sixteenth century (and probably many schoolmasters of the nineteenth century) would probably argue that modern chemistry with its fume cupboards and handling of particularly dangerous substances in gloveboxes is not "real" chemistry either.

\section{Discussion points:}

-What is the future of the chemistry laboratory-will people be eventually designed out of laboratories or is this unlikely?

- What will happen to teaching laboratories-will they be constructed according to the new laboratory style?

- Will undergraduates still do practical chemistry in the future?

\section{Sources and further reading}

With the exception of the sections on the social organisation of the laboratory and the school laboratory, the main source for this article is Morris, PJT (2015) The Matter Factory: A History of the Chemistry Laboratory. Reaktion, London and the sources cited therein. Other useful accounts can be found in James, FAJL (1989) The Development of the Laboratory: Essays on the Place of Experiment in Industrial Civilisation. American Institute of Physics, New York, which covers physics as well as chemistry; Jackson, CM (2017) Laboratorium In Handbuch Wissenschaftsgeschichte. JB Metzler, Stuttgart, pp. 244-255; and the special issue of Isis volume 99 , issue 4 , on laboratory history. For the nineteenth century laboratory, see Homburg, E (1999) The rise of analytical chemistry and its consequences for the development of the German chemical profession (1780-1860). Ambix 46:1-32 and Jackson, CM (2011) Chemistry as the defining science: discipline and training in nineteenth-century chemical laboratories. Endeavour 35:55-62. For the social organisation of the laboratory, see Morris, PJT (2021) "Aspects of the Social Organisation of the Chemical Laboratory in Heidelberg and Imperial College, London" in van Berkel, K and Homburg, E (eds.), The Modern Laboratory and the Changing Nature of the University, 1850-1950.Amsterdam University Press, Amsterdam. Industrial laboratories are covered by MeyerThurow, G (1982) The industrialization of invention: a case study from the German chemical industry. Isis 73:363-381 and Homburg, E. (1992) The emergence of research laboratories in the dyestuffs industry, 1870-1900. British Journal for the History of Science 25:91-111. For the special case of Apothecaries' Hall, see Simmons, A (2014) Stills, Status, Stocks and Science: The Laboratories at Apothecaries' Hall in the Nineteenth Century. Ambix 61:141-161. For school laboratories, see Brock, WH (2017) British school chemistry laboratories, 1830-1920. Ambix 64 43-65. For the instrumental revolution in chemistry, see Morris, PJT (ed.) (2002) From Classical to Modern Chemistry: The Instrumental Revolution. Royal Society of Chemistry, Cambridge and Reinhardt, C (2006) Shifting and Rearranging: Physical Methods and the Transformation of Modern Chemistry. Science History Publications, Sagamore Beach, MA. For modern laboratories, see Galison, P. and Thompson, E (eds.) (1999) The Architecture of Science. MIT Press, Cambridge, MA.

Funding No funding (information that explains whether and by whom the research was supported).

\section{Declarations}

Conflict of interest None.

Publisher's Note Springer Nature remains neutral with regard to jurisdictional claims in published maps and institutional affiliations. 